\title{
How much can elderly patients tell us about their medications?
}

\author{
Husayn Al Mahdy and David Gwyn Seymour \\ University Department of Geriatric Medicine, Cardiff Royal Infirmary (West Wing), Newport Road, \\ Cardiff CF2 ISZ, UK.
}

\begin{abstract}
Summary: Two hundred and sixty one patients attending a geriatric service were asked to give details of their usual medications without reference to drug bottles or written lists. Recall was tested in 4 categories: name of drugs, drug dosage, frequency of administration, and reason for the drug being prescribed. Drug recall was poor in all 4 categories, but particularly in respect of drug naming where only $10 \%$ of patients were able to give a complete list of their drugs. Out-patients were more knowledgeable about their medications than day hospital patients or inpatients. The rate of errors and omissions was correlated with increasing age, decreasing mental score, and to a lesser extent, number of drugs prescribed. Sixty-four percent of patients administered their own medications at home, and their ability to recall their medications was superior to that of other patients. The implications of the above findings are discussed.
\end{abstract}

\section{Introduction}

It is estimated that $75 \%$ of the population aged 75 years and over are on some form of medication. ${ }^{1}$ It is thus not surprising that adverse reactions to drugs are more commonly seen in the elderly than in the young, ${ }^{2}$ accounting for 10 to $15 \%$ of all admissions to geriatric units in some series. ${ }^{3,4}$ It has been suggested that the major preventable causes of adverse reactions to drugs in the elderly are inadequate clinical assessment leading to excessive prescribing, together with inadequate supervision of long-term medications. ${ }^{5}$ These factors are made worse by altered pharmacokinetics and pharmacodynamics associated with increasing age.

It is therefore crucial to have an accurate drug history when elderly patients are first seen in hospital. As the patient is the usual initial source of the drug history, major problems can arise if individual patients cannot recall their medications accurately. In addition, good knowledge of drugs and proper labelling of drug containers aid compliance. ${ }^{2,4,6-10}$ The present study was undertaken to assess the reliability of drug histories provided by a group of elderly patients, and to examine the factors which affected this reliability.

\footnotetext{
Correspondence: H. Al Mahdy, M.R.C.P.(UK)

Department of Health Care of the Elderly, Dulwich Hospital (North Wing), St Francis Road, London SE22 8DF, UK.

Accepted: 6 September 1989
}

\section{Patients and methods}

All patients admitted to an acute geriatric unit in Caerphilly District Miners' Hospital over a 4month period were interviewed by HAM within 12 hours of admission and asked about the medications they were taking at home. As we wished to test the reliability of the verbal history, patients were not allowed access to drug bottles or written lists while being interviewed. Over the same period the same interviewer also questioned patients attending the geriatric service as follow-up outpatients, and attenders of Day Hospital. The following background data were collected on each patient: (a) age, (b) sex, (c) social class (OPCS classification of previous occupation, with life-long housewives being classified according to their husband's status), (d) mental test score (using the 10-pint Qureshi and Hodkinson questionnaire ${ }^{11}$ ). (e) The person responsible for administering the drugs was also noted.

Patients were asked to give details of their medications in 4 areas.

(a) Name of the medication (here generic or trade names were equally acceptable). Even when patients could not name a drug they could often describe it in terms such as 'a little blue heart tablet'. It was thus often possible to test other aspects of medication knowledge even when the drug name was not given. A drug that the patient forgot to mention altogether, however, was coded as an error. 
(b) Dosage of drugs identified by the patient. The exact dosage was desired, although where drugs were marketed in only one strength, the number of tablets was accepted.

(c) Frequency of taking the drugs

(d) Reason for taking the drugs (broad descriptions such as 'a water tablet' for a diuretic, or 'a heart tablet' for digoxin were taken as correct.

The correctness of patients' responses were then checked by going through all the medications brought to the hospital, and by contacting carers or close relatives who had first-hand knowledge about drugs taken at home.

Errors in the drug information provided by the patient were recorded separately in the four categories given above, i.e. 'naming' errors, 'dosage' errors, 'frequency' errors, and 'reason' errors. Drugs which the patient failed to recall altogether were counted as errors for the purpose of the analysis. Various methods for expressing patient performance were considered, but two were finally selected:

1. Method 1 -number (or \%) of patients making NO errors. This method of expressing error is the one employed in Table $\mathrm{I}$.

2. Method 2 - error rate per patient. This is the method used in Figure 1 and Table II. Under Method 2, if a patient who was prescribed 5 drugs knew the name of 4 of them, the 'naming' error rate was $1 / 5 \times 100 \%=20 \%$. Note that the emphasis of Method 2 is quite different from that of Method 1. Under Method 1, a patient being prescribed 5 drugs would be coded as making a 'naming' error unless he or she was able to name all 5 drugs. The second method gives a more complete picture of patient knowledge, and is less 'harsh' on the patient who makes only a small number of errors.

Data were analysed by the SPSSX computer package. Confidence intervals for proportions were calculated as recommended by Gardner and Alt- $\operatorname{man}^{12}$ when $\mathrm{N}$ was over 50 and the proportion was between 0.1 and 0.9. Otherwise, an exact method of calculating confidence intervals was employed using Documenta Geigy Scientific Tables.

\section{Results}

\section{General information}

Three hundred and eighteen consecutive patients were questioned, but 29 of these were excluded from the study at the onset because of dysphasia, delirium, stupor, blindness, or severe deafness. A further 15 patients were subsequently excluded, because their medication regimen could not be verified. Of the remaining 274 patients, 13 were not being prescribed medications at home. The results that follow therefore refer to 261 patients. Of these, 66 were attending day hospital, 88 were outpatients, and 107 were in-patients.

The age range was between 65 and 97 years. Sixty-six percent of the patients were women, and $61 \%$ were aged 75 years or over. The population was drawn from a Welsh mining area, and $13 \%$ of patients were in Social Class I or II, $67 \%$ were in Social Class III, and the remainder were Classes IV or V. Sixty-seven percent of patients had mental test scores in the normal range ( 8 points or over $\left.{ }^{11}\right)$, but $6.5 \%$ scored very poorly (3.5 points or less).

Of the 261 patients studied, $166(64 \%)$ administered their own drugs while a further $30 \%$ were given drugs by a family member or friend. In only $6 \%$ of cases were medications administered by a health or social services professional. Only $38 \%$ of day hospital patients administered their own drugs at home, reflecting the greater level of dependency of this group.

The mean number of drugs prescribed was 3.8 ,

Table I Percentage of patients making no errors or omissions when describing the medications which they were taking at home

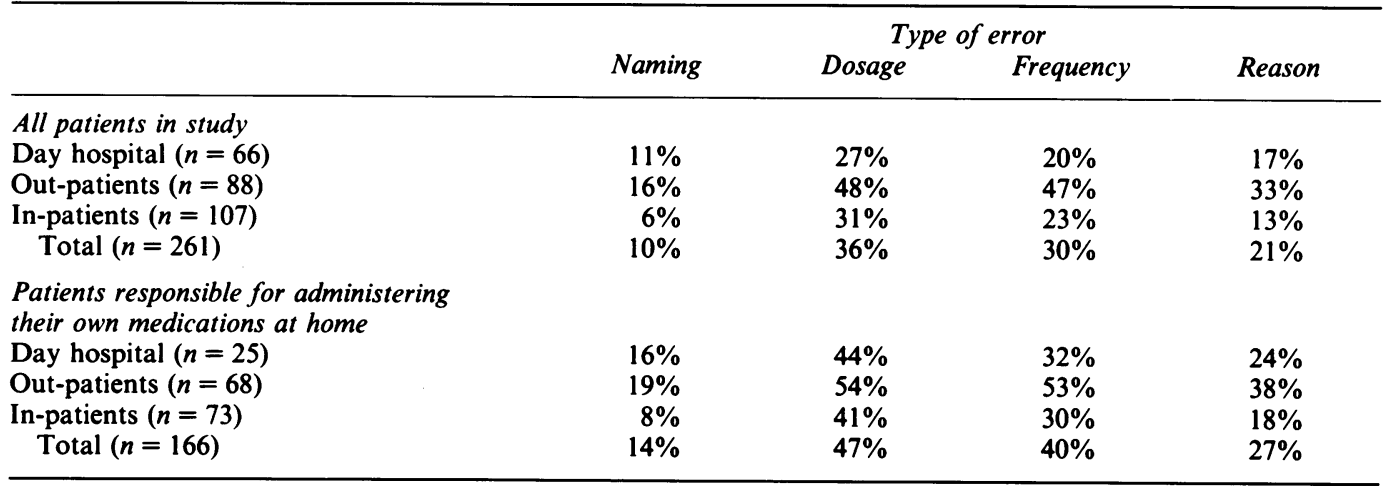


the median was 4 , and the range was between 0 and 11 medications. In addition, $12 \%$ of patients said they were taking one 'over the counter' drug and $3 \%$ were taking two such drugs.

Fifty-one percent of the drug containers were inappropriately labelled in that either the name, dose, or the frequency of administration of the drug was missing. The commonest inappropriate label was 'to be taken as directed'.

\section{Patients making no errors (Table I)}

'Naming' errors Only $10 \%$ of patients could name all their medications correctly. Out-patients performed best in this respect and in-patients worst. When analysis was confined to the 166 patients who administered their own drugs at home, $14 \%$ could give the names of all their medications.

'Dosage' errors Just over a third (36\%) of all patients gave the dosage of their medications with complete accuracy. Again, the best performance was seen in the out-patients who were free of error in almost $50 \%$ of cases. In contrast, only 1 in 4 day hospital patients made no errors of dosage when asked about their drugs under the standardized conditions of the study. Of patients administering their own drugs at home, $47 \%$ made no errors.

'Frequency' errors The pattern of errors in response to questions about drug frequency was very similar to that of dosage errors, with a $70 \%$ error rate overall. Day hospital patients made the most errors, and out-patients the least. Of patients administering their own drugs, $60 \%$ made one or more errors.

'Reason' errors Only 1 patient in 5 could give satisfactory reasons for taking all of their medications. Again, the out-patients performed best, with 1 patient in 3 achieving complete accuracy. Even among the 166 patients who administered their own drugs, only $27 \%$ were free from error under the conditions of testing used in the present study.

\section{Error rate per patient (Table II and Figure 1)}

The rates of error per patient in each of the four categories (naming, dosage, frequency, and reason) are shown in Figure 1. This shows a spectrum of error rates ranging from category 0 where no errors were made, to category IV which embraced patients who made errors in $75 \%$ or more of their medications. It can be seen from Figure 1 that the distribution of error rates in the four categories is 'U-shaped' rather than Gaussian, and so non-parametric statistics have been used in analysis.

Patient characteristics and rates of error - The relationship between medication error rates and the five patient characteristics of sex, age, social class, mental score, and number of prescribed drugs is examined in Table II. Statistical correlations have been sought using the non-parametric Spearman correlation coefficient $(\rho)$. When multiple statistical tests are being performed in this way there is a danger that a number of spurious 'statistically significant' associations will appear by chance alone. ${ }^{13}$ One approach to reduce this problem is to demand a more stringent $P$ value than 0.05 . In Table $I$, only $P$ values of 0.01 or less have been highlighted, and it can be seen that sex was not correlated with any aspect of medication error. Age was positively correlated with error rates of naming, dosage, frequency and reason while mental score was negatively correlated with all these error rates. Social class was correlated with naming errors only. The number of drugs prescribed was correlated positively with error rates of dosage and frequency, but not with naming and reason. When the analyses were repeated on those 166 patients who administered their own medications, the same trends were seen, but the $\rho$ values were usually smaller.

It was thought that some of the correlations seen in Table II might have arisen spuriously because the patient characteristics (of sex, age, class, mental score, and number of medications) were correlated with one another. A correlations matrix between the five patient characteristics was therefore constructed. The only correlation to attain a $P$ value of
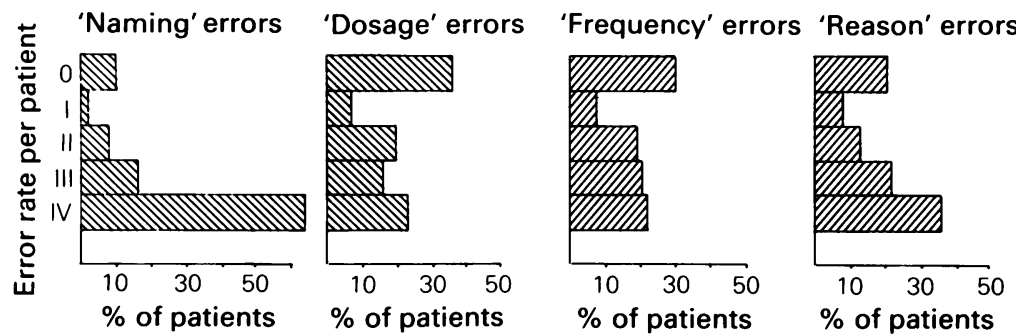

Figure 1 Rate of medication error per patient (as defined in Patients and methods); $0=0 \%, \mathrm{I}=>0 \%$ to $25 \%$, II $=>25 \%$ to $50 \%$, III $=>50 \%$ to $75 \%$, IV $=>75 \%$. Total number of patients $=261$. 
Table II Spearman (non-parametric) rank correlation coefficients between patient characteristics and medication error rates

\begin{tabular}{|c|c|c|c|c|}
\hline & $\begin{array}{c}\text { 'Naming' } \\
\text { errors }\end{array}$ & $\begin{array}{c}\text { 'Dosage' } \\
\text { errors }\end{array}$ & $\begin{array}{c}\text { 'Frequency' } \\
\text { errors }\end{array}$ & $\begin{array}{c}\text { 'Reason' } \\
\text { errors }\end{array}$ \\
\hline Sex $($ male $=1$, female $=2)$ & $\begin{array}{l}0.045 \\
0.039\end{array}$ & $\begin{array}{r}-0.014 \\
0.002\end{array}$ & $\begin{array}{l}-0.060 \\
-0.089\end{array}$ & $\begin{array}{l}0.018 \\
0.034\end{array}$ \\
\hline Age (in years) & $\begin{array}{l}0.032^{\star *} \\
0.250^{*}\end{array}$ & $\begin{array}{l}0.303^{\star \star} \\
0.133\end{array}$ & 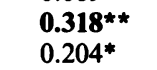 & $\begin{array}{l}0.297^{* *} \\
0.192\end{array}$ \\
\hline Social class (I to $\mathrm{V}$ ) & $\begin{array}{l}0.168^{\star} \\
0.178\end{array}$ & $\begin{array}{l}0.103 \\
0.033\end{array}$ & $\begin{array}{l}0.098 \\
0.011\end{array}$ & $\begin{array}{l}0.130 \\
0.092\end{array}$ \\
\hline Mental score ( 0 to 10$)$ & $\begin{array}{l}-0.438^{\star *} \\
-0.336^{* *}\end{array}$ & $\begin{array}{l}-0.455^{\star \star} \\
-0.200^{*}\end{array}$ & $\begin{array}{l}-0.462^{\star \star} \\
-0.185\end{array}$ & $\begin{array}{l}-0.496^{* *} \\
-0.285^{* *}\end{array}$ \\
\hline Number of prescribed drugs & $\begin{array}{l}-0.076 \\
-0.059\end{array}$ & $\begin{array}{l}0.2288^{\star *} \\
0.349^{* *}\end{array}$ & $\begin{array}{l}0.206^{* *} \\
0.315^{* *}\end{array}$ & $\begin{array}{l}0.002 \\
0.042\end{array}$ \\
\hline
\end{tabular}

${ }^{*}=P<0.01,{ }^{* *}=P<0.001 ; P$ values between 0.05 and 0.01 have not been marked for reasons stated in the text. Bold type refers to all patients, $n=261$; normal type refers to patients administering their own drugs, $n=166$

0.01 or less were mental score and age $(\rho=-0.363$, $P<0.001)$ and mental score and number of drugs $(\rho=0.175, P<0.01)$. Because of this the analyses of Table II were repeated after patients with low mental scores were excluded. When this was done, age still appeared as a risk factor which was correlated with all categories of medication error rate, but $\rho$ values were approximately 0.1 lower. A more sophisticated multivariate analysis was not thought warranted.

\section{Discussion}

It might be argued that we were being 'unfair' to our elderly patients by testing drug knowledge without letting them first consult medicine containers, written lists, or their carers. However, we set out to simulate the situation, all too common in clinical practice, where none of these sources of information is readily available. For the same reason, drugs which the patient forgot to mention altogether were coded as if an error had been made. Even allowing for these rather strict requirements, the level of errors made by patients in this study might appear surprisingly high, but error rates between $25 \%$ and $82 \%$ have been found in previous studies, depending on the definitions used ${ }^{8.14-16}$ The lack of standardization definitions is a problem when comparing different reports, and we have therefore defined our methods with some care. Two main methods of definition have been used. The first, which is employed in Table $I$, is the more stringent of the two, and it is probably the second method (Table II and Figure 1) which gives the more complete picture. Other methods could be employed, and in reading the literature it is important to note whether results refer to numbers of patients or numbers of medications, whether errors are expressed as absolute numbers or as propor- tions, and whether drugs that patients omit to mention altogether are excluded from the analysis.

Our patients tended to be more accurate about the 'mechanical' aspects of drug usage (dosage details and frequency of administration) than those aspects which required greater interest and understanding (drug name and reason for administration). This suggests that many elderly patients take their drugs without understanding the reason why, a conclusion also reached by Smith and Andrews. ${ }^{17}$ Even though a mechanical approach to drug taking might achieve reasonable levels of drug compliance in some individuals, the usual experience has been that drug knowledge and compliance go hand in hand. ${ }^{9,10,16}$

Good drug knowledge in the patient would seem desirable for several reasons. Most physicians in modern geriatric practice would aim to involve patients closely in all aspects of their therapy, including their medication plan. ${ }^{18}$ Studies in Britain $^{19,20}$ and the USA $^{18}$ have also shown that patients themselves would like more information about their drugs. It is very desirable that patients report side effects of drugs promptly. It is difficult to see how this can happen if patients have little knowledge of the expected actions of their individual drugs.

The present study has examined a number of factors which might influence drug knowledge. Sex was not related to the ability to recall drug information, in keeping with the findings of Parkin et al..$^{15}$ Unlike these earlier authors, however, we found that age was positively correlated with many types of medication error, even when the negative correlation between age and mental score was allowed for. In our study, social class was related to the rate of 'naming' errors but was otherwise a factor of little importance. Parkin et al. ${ }^{15}$ found an association between social class and drug compliance, but this did not attain the conventional level of statistical significance. 
Studies in the past have shown that the greater the number of drugs that are given, the worse is patient compliance. ${ }^{4,5,10,15}$ In our study the number of drugs prescribed was correlated with the error rate per patient in the categories of 'dosage' and 'frequency' but not in the categories of 'naming' and 'reason'. The best single predictor of the quality of drug recall in the present study was the mental score, in keeping with previous experience. ${ }^{5,8,10}$

Patients who administered their own drugs were able to give fuller drug histories than the remainder. Over two thirds of the out-patients and in-patients administered their own drugs at home, while only $38 \%$ of day hospital patients were entrusted with giving their own medications, reflecting the increased medical, social and memory problems of patients selected for day hospital follow-up.

A number of measures can be undertaken to improve drug knowledge in the elderly, with the expectation that both better compliance and improved ability to give a drug history should follow. In the first place better instruction of patients. Patient counselling can be effective in increasing drug knowledge and compliance ${ }^{8-10}$ although 15 minutes or more is probably required for this

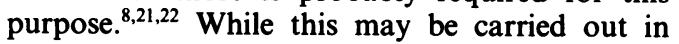
in-patients on the day of discharge, the last-minute nature of such instruction may detract from its effectiveness. ${ }^{14}$ The importance of a combination of written and verbal counselling has been stressed in several reports. ${ }^{5,10,18}$ Written instructions begin (and unfortunately often end) with the label on the drug container, and the findings of this study that half of the drug containers dispensed in the community were inadequately labelled (usually due to inadequacies in the original prescription) is a matter of continuing concern. Perhaps pharmacists should be required to refuse to dispense prescriptions which contain inadequate information such as 'to be taken as directed'. Even where labels are accurate, some improvements are possible, and instructions which may appear self-evident to the prescriber may be widely misinterpreted by the elderly patient. ${ }^{23}$ Drug labels intended for the elderly may benefit from additional features such as large print, tie-on labels, and extra comments such as 'water tablets'. $.24-26$

In addition to the drug label, written material can include separate instruction sheets and a drug record card, with special cards being issued to patients taking steroids and anticoagulants. An idea which has been extensively developed in the USA $^{18,27}$ and which is being evaluated in Britain $^{20,28,29}$ is to supply patients with Patient Package Inserts (PPIs) which given details in lay language about drug actions and possible side effects.

Secondly, reducing the number of drug prescribed will improve drug knowledge. Drug errors are particularly likely to occur when more than three drugs are prescribed. ${ }^{5}$ In the present study the mean number of drugs was 3.8, suggesting considerable scope for improvement.

Although counselling can reduce the rate of errors even in patients with impaired mental function, ${ }^{8}$ it might also be preferable to arrange for another person to administer medications where mental function is poor. ${ }^{5}$ The over-85s also appear to be a particularly vulnerable group. ${ }^{5}$ Where patients are highly unlikely to be able to provide accurate drug histories despite counselling, they should carry an up-to-day list of their drugs with them at all times.

\section{Acknowledgements}

We gratefully acknowledge the statistical advice of $\mathrm{Dr}$ Tim Peters, Lecturer in Medical Statistics at the University of Wales College of Medicine. We would also like to thank Dr Mukund Joglekar for allowing us access to patients under his care and to local general practitioners for their cooperation with the study.

\section{References}

1. Skegg, D.C.G., Doll, R. \& Perry, J. Use of medicines in general practice. $\mathrm{Br}$ Med J 1977, 1: 1561-1563.

2. Caird, F.I. Towards rational drug therapy in old age. $J R$ Coll Physicians Lond 1985, 19: 235-239.

3. Williamson, J. \& Chopin, J.M. Adverse reactions to prescribed drugs in the elderly: a multicentre investigation. Age Ageing 1980, 9: 73-80.

4. Bliss, M.R. Prescribing for the elderly. $\mathrm{Br}$ Med J 1981, 283: 203-206.

5. Royal College of Physicians. Medication for the elderly. $J R$ Coll Physicians Lond 1984, 18: 7-17.

6. Office of Health Economics. Keep on taking the tablets, a review of patient non compliance. Office of Health Economics, London. 1983, No 21.

7. Eraker, S.A., Kirscht, J.P. \& Baker, M.H. Understanding and improving patient compliance. Ann Intern Med 1984, 100: 258-268.

8. Macdonald, E.T., Macdonald, J.B. \& Phoenix, M. Improving drug compliance after hospital discharge. Br Med J 1977, 2: 618-621.

9. Johnson, M.W., Mitch, W.E., Sherwood, J., Lopes, L., Schmidt, A. \& Hartley, H. The impact of a drug information sheet on the understanding and attitude of patients about drugs. JAMA 1986, 256: 2722-2724.

10. Christopher, L.J. Drug prescribing and compliance in the elderly. In: Swift, C.G. (ed) Clinical Pharmacology in the Elderly. Marcel Dekker, New York and Basel. 1987, pp. $103-117$.

11. Seymour, D.G., Henschke, P.J., Cape, R.D.T. \& Campbell, A.J. Acute confusional states in the elderly: the role of dehydration/volume depletion, physical illness and age. Age Ageing 1980, 3: 137-146. 
12. Gardner, M.J. \& Altman, D.G. Confidence intervals rather than $P$ values: estimation rather than hypothesis testing. $\mathrm{Br}$ Med J 1986, 292: 746-750.

13. Pocock, S.J., Hughes, M.D. \& Lee, J.L. Statistical problems in the reporting of clinical trials. A survey of three medical journals. N Engl J Med 1987, 317: 426-432.

14. Stewart, R.B. \& Cluff, L.E. A review of medication errors and compliance in ambulant patients. Clin Pharmacol Ther 1972, 13: 463-468.

15. Parkin, D.M., Henney, C.R., Quirk, J. \& Crooks, J. Deviation from prescribed drug treatment after discharge from hospital. Br Med J 1976, 2: 686-688.

16. Landahl, S. Drug treatment in 70-82-year-old persons. A longitudinal study. Acta Med Scand 1987, 221: 179-184.

17. Smith, P. \& Andrews, J. Drug compliance not so bad, knowledge not so good - the elderly after hospital discharge. Age Ageing 1983, 12: 336-342.

18. Gotsch, A.R. \& Ligouri, S. Knowledge, attitude and compliance dimensions of antibiotic therapy with PPIs. A community pharmacy-based study. Medical Care 1982, 20: $581-595$.

19. Crooks, J. \& Parkin, D.M. The problem of compliance in drug therapy. In: Shanks, R.G. (ed) Topics in Therapeutics 3. Pitman Medical, London; 1977, pp. 116-131.

20. Ridout, S., Waters, W.E. \& George, C.F. Knowledge of and attitudes to medicines in the Southampton community. $\mathrm{Br} \mathrm{J}$ Clin Pharmacol 1986, 21: 701-712.
21. American Society of Hospital Pharmacists. Guidelines on pharmacist conducted patient counselling. Am J Hosp Pharm 1984, 41: 331-333.

22. Johnston, M., Clarke, A., Mundy, K., Cromarty, E. \& Ridout, K. Facilitating comprehension of discharge medication in elderly patients. Age Ageing 1986, 15: 304-306.

23. Hallworth, R.B. \& Goldberg, L.A. Geriatric patients understanding of labelling of medicines. $\mathrm{Br} \mathrm{J}$ Pharm Practice 1984, January: 6-14.

24. Veitch, G.B.A. \& Wright, B.J. The labelling of dispensed medicines for the elderly patient: a pilot survey. J Clin Hosp Pharm 1982, 7: 187-194.

25. Anon. What can we expect the label to tell the patient? Drug Ther Bull 1985, 23: 87-88.

26. Zuccollo, G \& Liddell, H. The elderly and the medication label: doing it better. Age Ageing 1985, 14: 371-376.

27. Health and Public Policy Committee, American College of Physicians. Drug information for patients. Ann Intern Med 1986, 104: 121 .

28. Hermann, F., Herxheimer, A. \& Lionel, N.D.W. Package inserts for prescribed medicines: what minimum information do patients need? $\mathrm{Br}$ Med J 1978, 2: 1132-1135.

29. George, C.F., Waters, W.E. \& Nicholas, J.A. Prescription information leaflets: a pilot study in general practice. $\mathrm{Br} \mathrm{Med}$ $J$ 1983, 287: 1193-1196. 